\title{
Kinerja Sektor Industri Kota Bandung Berdasarkan Analisis Shift Share pada Model Input Output
}

\author{
TETI SOFIA YANTI \\ Program Studi Statistika, Fakultas MIPA, Universitas Islam Bandung \\ Email: tetisofiayanti@gmail.com
}

\begin{abstract}
ABSTRAK
Tabel Input Output disusun untuk keperluan perencanaan dan evaluasi hasil-hasil pembangunan yang bersifat menyeluruh baik skala nasional maupun skala yang lebih kecil (tingkat kabupaten/kota), model pendekatan perencanaan pembangunan wilayah dapat menggunakan model analisis input-output. Pembangunan Kota Bandung merupakan bagian yang tidak terpisahkan dari pembangunan Jawa Barat bahkan nasional, dalam rangka mencapai sasaran pembangunan yang disesuaikan dengan potensi dan permasalahan pembangunan di daerah. Di bidang ekonomi, Kota Bandung harus mampu memobilisasi serta mengelola produksi, alokasi dan distribusi berbagai sumberdaya yang dimilikinya sehingga menghasilkan produk unggulan yang memiliki keunggulan daya saing komparatif maupun kompetitif, baik untuk pasar lokal, regional, nasional bahkan internasional. Melalui analisis shift share dalam model input ouput, kinerja sektor ekonomi Kota Bandung dibandingkan dengan tingkat provinsi dapat terlihat.
\end{abstract}

Kata Kunci: Model Input Output, Analisis Shift Share, Keterkaitan Antar Sektor, Klasifikasi Industri, Sektor Unggulan.

\section{PENDAHULUAN}

Visi Kota Bandung adalah terwujudnya Kota Bandung yang unggul, nyaman dan sejahtera. Sedangkan salah satu misinya adalah membangun masyarakat yang mandiri, berkualitas dan berdaya saing, serta membangun perekonomian yang kokoh, maju, dan berkeadilan. Agar misi tersebut tercapai, maka semestinya Kota Bandung harus mampu mengeluarkan dan mengembangkan kemampuannya dalam mengembangkan sumber daya yang ada.

Pembangunan Kota Bandung merupakan bagian yang tidak terpisahkan dari pembangunan Jawa Barat bahkan nasional, dalam rangka mencapai sasaran pembangunan yang disesuaikan dengan potensi dan permasalahan pembangunan di daerah. Di bidang ekonomi, pembangunan daerah meletakkan pembangunan sektor-sektor melalui terwujudnya struktur ekonomi yang seimbang di berbagai sektor, untuk itu kinerja berbagai sektor ekonomi perlu diperhatikan guna meningkatkan perekonomian daerah.

Kota Bandung harus mampu memobilisasi serta mengelola produksi, alokasi dan distribusi berbagai sumberdaya yang dimilikinya sehingga menghasilkan produk-produk unggulan yang memiliki keunggulan daya saing komparatif maupun kompetitif, baik untuk pasaran lokal, regional, nasional bahkan internasional. Salah satu alat yang bisa digunakan untuk melakukan analisis tersebut adalah model input output. Melalui analisis shift share dalam model input ouput, kinerja sektor ekonomi Kota Bandung dibandingkan dengan tingkat provinsi dapat terlihat.

\section{ANALISIS INPUT OUTPUT}

Untuk keperluan perencanaan dan evaluasi hasil-hasil pembangunan yang bersifat menyeluruh baik skala nasional maupun skala yang lebih kecil (tingkat kabupaten/kota), model pendekatan perencanaan pembangunan wilayah dapat menggunakan model analisis input-output. Melalui model analisis input output dapat dilihat keterkaitan antar sektor dalam perekonomian sehingga dapat diketahui kinerja suatu sektor dalam perekonomian dan langkah kebijakan perekonomian yang tepat dalam pembangunan (Amir, 2005). 


\section{Matriks Koefisien Input (Matriks Teknologi)}

Misalkan perekonomian terdiri dari dua sektor ekonomi, memiliki variabel-variabel input antara $(\mathrm{Z})$, output $(\mathrm{X})$, permintaan akhir $(\mathrm{Y})$ dan variabel input primer (W). Keempat variabel tersebut jika diuraikan dalam bentuk matriks sebagai berikut:

$Z=\left(\begin{array}{ll}z_{11} & z_{12} \\ z_{21} & z_{22}\end{array}\right), \mathbf{X}=\left(\begin{array}{l}X_{1} \\ X_{2}\end{array}\right), \mathbf{Y}=\left(\begin{array}{c}C_{1}+G_{1}+I_{1}+E_{1} \\ C_{2}+G_{2}+I_{2}+E_{2}\end{array}\right)=\left(\begin{array}{l}Y_{1} \\ Y_{2}\end{array}\right), W=\left(\begin{array}{cc}L_{1} & L_{2} \\ N_{1} & N_{2}\end{array}\right)$

dengan:

$\mathrm{C}=$ konsumsi rumah tangga, $\mathrm{G}=$ belanja pemerintah, $\mathrm{I}=$ investasi

$\mathrm{E}=$ ekspor, $\mathrm{L}=$ tenaga kerja, $\mathrm{N}=$ nilai tambah

Hubungan antara $Z$ dan $X$ menyatakan koefisien teknologi atau koefisien input-output yaitu:

$$
a_{i j}=\frac{z_{i j}}{X_{j}}
$$

Jika terdapat $\mathrm{n}$ sektor di dalam perekonomian, maka akan terdapat ( $\mathrm{x} \mathrm{x}$ ) koefisien teknologi yang disebut matriks teknologi (A).

\section{Matriks Pengganda}

Matriks pengganda (I-A)-1digunakan untuk melakukan analisis dampak atau multiplier effect. Matriks pengganda atau matriks kebalikan Leontif dirumuskan sebagai berikut:

$$
(\mathrm{I}-\mathrm{A})^{-1}=\left(\left(\begin{array}{cccc}
1 & 0 & \ldots & 0 \\
1 & 1 & \ldots & 0 \\
\ldots & \ldots & \ldots & . \\
0 & 0 & \ldots & 1
\end{array}\right)-\left(\begin{array}{cccc}
a_{11} & a_{12} & \ldots & a_{1 n} \\
a_{21} & a_{22} & \ldots & a_{2 n} \\
\ldots & \ldots & \ldots & \ldots \\
a_{n 1} & a_{n 2} & \ldots & a_{n n}
\end{array}\right)\right)^{-1}=\left(\begin{array}{cccc}
b_{11} & b_{12} & \ldots & b_{1 n} \\
b_{21} & b_{22} & \ldots & b_{2 n} \\
\ldots & \ldots & \ldots & \ldots \\
b_{n 1} & b_{n 2} & \ldots & b_{n n}
\end{array}\right)
$$

Dalam hubungannya untuk setiap sektor ekonomi dapat dijelaskan melalui indeks daya penyebaran $(\alpha)$ dan indeks derajat kepekaan $(\beta)$ dirumuskan sebagai berikut:

$\alpha_{j}=\frac{\sum_{i=1}^{n} b_{i j}}{(1 / n) \sum_{i} \sum_{j} b_{i}}, \quad \beta_{i}=\frac{\sum_{j=1}^{n} b_{i j}}{(1 / n) \sum_{i} \sum_{j} b_{i}}$

dengan :

$\alpha \mathrm{j}=$ indeks daya penyebaran sektor $\mathrm{j}$

$\beta \mathrm{I} \quad=$ indeks derajat kepekaan sektor $\mathrm{i}$

$\sum_{i=1}^{n} b_{i j} \quad=$ jumlah daya penyebaran sektor $\mathrm{j}$

$\sum_{j=1}^{n} b_{i j} \quad=$ jumlah derajat kepekaan sektor $\mathrm{i}$

\section{Model Shift Share}

Analisis shift share merupakan teknik yang sangat berguna dalam menganalisis perubahan ekonomi wilayah dibandingkan perekonomian yang lebih luas (wilayah referensi) selama selang 
waktu tertentu. Tujuan dari analisis shift share adalah untuk menentukan kinerja atau produktivitas kerja perekonomian wilayah dengan membandingkan dengan wilayah yang lebih luas (wilayah referensi). Dengan demikian, analisis ini akan memberikan hasil perhitungan yang dapat menentukan posisi kekuatan atau kelemahan suatu industri di wilayah dibandingkan dengan industri yang sama di wilayah referensi.

Adapun perhitungan untuk analisis shift share dinyatakan sebagai berikut:

$$
\mathrm{x}_{i t}-\mathrm{x}_{i 0}=\mathrm{x}_{i 0}\left(\left(\frac{X_{t}}{X_{0}}\right)-1\right)+\mathrm{x}_{i 0}\left(\left(\frac{X_{i t}}{X_{i 0}}\right)-\left(\frac{X_{t}}{X_{0}}\right)\right)+\mathrm{x}_{i 0}\left(\left(\frac{\mathrm{x}_{i t}}{\mathrm{x}_{i 0}}\right)-\left(\frac{X_{t}}{X_{0}}\right)\right)
$$

dengan:

$\mathrm{x}_{\mathrm{i} 0}=$ jumlah output sektor i wilayah di tahun awal.

$\mathrm{x}_{\mathrm{it}}=$ jumlah output sektor $\mathrm{i}$ wilayah di tahun akhir.

$\mathrm{X}_{\mathrm{i} 0}=$ jumlah output sektor $\mathrm{i}$ wilayah referensi di tahun awal.

$\mathrm{X}_{\mathrm{it}}=$ jumlah output sektor $\mathrm{i}$ wilayah referensi di tahun akhir.

Komponen $\mathrm{G}$ digunakan sebagai dasar (benchmark) untuk mengukur pertumbuhan ekonomi wilayah melalui perubahan pada rasio tenaga kerja/output wilayah dengan tenaga kerja/output wilayah nasional. Komponen $\mathrm{M}$ dan $\mathrm{S}$ (pergeseran porposional dan pergeseran diferensial) sering disebut komponen shift (PP+PD) dalam shift share analysis. Nilai dari komponen ini dapat dijadikan acuan pada analisis shift share, yaitu jika didapatkan nilai shift dari suatu sektor adalah posistif, maka sektor-sektor tersebut dapat dikatakan sebagai sektor yang relatif lebih maju dibandingkan dengan sektor yang sama di wilayah referensi, dan sebaliknya jika nilai shift share dari suatu sektor adalah negatif maka sektor tersebut dapat dikatakan sektor yang mundur.

Analisis shift share memberikan informasi tentang kinerja perekonomian ke dalam tiga kelompok yang berhubungan satu sama lain, yaitu:

a. Pertumbuhan ekonomi wilayah yang dikaitkan dengan pertumbuhan nasional atau wilayah referensi. Jika suatu wilayah tumbuh dengan tingkat yang sama dengan pertumbuhan nasionalnya maka wilayah tersebut akan dapat mempertahankan sumbangannya terhadap perekonomian (kesempatan kerja) nasional. Oleh karena itu, komponen ini disebut sebagai komponen "Share".

b. Pergeseran proporsional (proportional Shift), mengukur pertumbuhan relatif suatu sektor di wilayah dibandingkan dengan perekonomian wilayah referensi.

c. Pergeseran Differensial (Diferential Shift), mengkur seberapa jauh daya saing industri suatu wilayah dibandingkan dengan wilayah referensi. Jika pergeserannya bernilai positif maka industri tersebut lebih tinggi daya saingnya dibandingkan dengan industri yang sama pada wilayah referensi.

\section{HASIL DAN PEMBAHASAN}

Analisis shift share dan analisis keterkaitan antar sektor dilakukan terhadap 40 sektor ekonomi yang terdapat di Kota Bandung dan Provinsi Jawa barat. Nilai setiap komponen akan dijadikan analisis perbandingan kinerja sektor eonomi di Kota Bandung terhadap Jawa barat. Hasil selengkapnya terdapat pada Tabel 1 dan Gambar 1.

Nilai dari tiap komponen Shift Share $(\mathrm{G}+\mathrm{S}+\mathrm{M})$ dijadikan acuan dalam analisis. Tanda positif pada shift share memperlihatkan sektor ekonomi yang lebih maju dari sektor sejenis pada wilayah pembanding. Sebesar 70\% sektor ekonomi di Kota Bandung relatif maju dibandingkan dengan sektor yang sama di tingkat provinsi, dimana lima sektor relatif paling maju adalah: Industri Pengolahan Lainnya; Perdagangan; Industri tekstil dan pakaian jadi; Hotel; Industri makanan dan minuman. Melalui analisis keterkaitan, sektor Perdagangan menjadi "top leader", sektor tersebut outputnya akan meningkat sebesar Rp.40,19 juta apabila permintaan akhir di seluruh sektor meningkat sebesar 1 juta rupiah, dan apabila sektor tersebut meningkat permintaan akhirnya sebesar 1 juta rupiah makan akan mendorong output seluruh sektor meningkat sebesar Rp. 2,74 juta. 


\section{Teti Sofia Yanti}

Tabel 1. Nilai Shift Share 40 Sektor Ekonomi Kota Bandung

\begin{tabular}{|c|c|c|c|c|c|c|c|}
\hline \multirow{2}{*}{ Kode } & \multirow{2}{*}{ Sektor } & \multicolumn{2}{|c|}{ Komponen S } & \multicolumn{2}{|c|}{ Komponen $\mathrm{M}+\mathrm{S}$} & \multicolumn{2}{|c|}{ Shift Share } \\
\hline & & Nilai & Tanda & Nilai & Tanda & Nilai & Tanda \\
\hline (1) & (2) & (3) & (4) & (5) & (6) & (7) & (8) \\
\hline 1 & Tanaman Bahan Makanan & 1646274.8 & + & 1707983.9 & + & 1862056 & + \\
\hline 2 & $\begin{array}{l}\text { Ternak, Unggas, dan Hasil- } \\
\text { Hasilnya }\end{array}$ & 870256.8 & + & 958374.64 & + & 1178383 & + \\
\hline 3 & $\begin{array}{l}\text { Perikanan dan Hasil Perikanan } \\
\text { Lainnya }\end{array}$ & -89283 & - & 17671.259 & + & 284709.3 & + \\
\hline 4 & Hasil Pertanian Lainnya & 108582.5 & + & 150809.23 & + & 256238.7 & + \\
\hline 5 & $\begin{array}{l}\text { Barang Tambang dan Hasil } \\
\text { Galian Lainnya }\end{array}$ & 21712 & + & -72469.409 & - & 95694.6 & + \\
\hline 6 & $\begin{array}{c}\text { Industri Makanan, Minuman dan } \\
\text { Tembakau }\end{array}$ & 5826506.4 & + & 7279159.9 & + & 10003856 & + \\
\hline 7 & $\begin{array}{c}\text { Industri Tekstil, Pakaian Jadi, } \\
\text { Kulit dan alas kaki }\end{array}$ & 25009111 & + & 25729256 & + & 30215549 & + \\
\hline 8 & $\begin{array}{l}\text { Industri Kayu, Bambu, Rotan dan } \\
\text { Furniture }\end{array}$ & -22298468 & - & -23966174 & - & -5639948 & - \\
\hline 9 & $\begin{array}{l}\text { Industri Kertas dan Barang- } \\
\text { barang dari Kertas }\end{array}$ & -2417043.7 & - & -4703734.5 & - & -1694776 & - \\
\hline 10 & $\begin{array}{l}\text { Industri Percetakan dan } \\
\text { Penerbitan } \\
\end{array}$ & -5723710.8 & - & -9824411.4 & - & -4428475 & - \\
\hline 11 & Industri Pengilangan Minyak & -1818745.4 & - & 762144.85 & + & 2821072 & + \\
\hline 12 & $\begin{array}{c}\text { Industri Kimia dan Barang- } \\
\text { Barang dari Kimia }\end{array}$ & -6203394.2 & - & -6876772.5 & - & -745562 & - \\
\hline 13 & $\begin{array}{l}\text { Industri Karet dan barang-barang } \\
\text { dari karet }\end{array}$ & -1453796 & - & -1660124 & - & 218523 & + \\
\hline 14 & $\begin{array}{l}\text { Industri Barang-Barang dari } \\
\text { Plastik kecuali Furniture }\end{array}$ & -54309.3 & - & -174089.85 & - & 916529.5 & + \\
\hline 15 & $\begin{array}{c}\text { Industri Barang Galian bukan } \\
\text { Logam }\end{array}$ & -1443231.1 & - & -2050908.6 & - & -670026 & - \\
\hline 16 & Industri Logam Dasar & -170804 & - & -1317025 & - & -414454 & - \\
\hline 17 & Industri Pengolahan Lainnya & -385981.5 & - & 176683353 & + & $1.88 \mathrm{E}+08$ & + \\
\hline 18 & Listrik & 1017943.3 & + & 704179.65 & + & 1816048 & + \\
\hline 19 & Air Bersih & -2337207.9 & - & -3047729.9 & - & -529888 & - \\
\hline 20 & Konstruksi & -2184906.6 & - & -1030882.8 & - & 6322887 & + \\
\hline 21 & $\begin{array}{l}\text { Industri kendaraan Bermotor, } \\
\text { karoseri, dan perlengkapannya }\end{array}$ & -7494989.5 & - & -1886570.1 & - & 4614249 & + \\
\hline 22 & Perdagangan & 45628837 & + & 54295387 & + & 64340942 & + \\
\hline 23 & Hotel & -38751979 & - & -13458559 & - & 15859498 & + \\
\hline 24 & Restoran & 2426601.7 & + & 4432776.6 & + & 6758170 & + \\
\hline 25 & Jasa Angkutan Kereta Api & -3410720.3 & - & -1122402.5 & - & 2295226 & + \\
\hline 26 & Jasa Angkutan Jalan & 6150337.3 & + & 6616975.7 & + & 7313905 & + \\
\hline 27 & Jasa Angkutan Udara & -410920.4 & - & 1584736.2 & + & 4565272 & + \\
\hline 28 & Jasa Penunjang Angkutan & -2563407.5 & - & -949033.61 & - & 1462052 & + \\
\hline 29 & Jasa Komunikasi & 3298812.4 & + & 3639810.6 & + & 4149095 & + \\
\hline 30 & $\begin{array}{c}\text { Jasa Bank dan Lembaga } \\
\text { Keuangan }\end{array}$ & -15441459 & - & -22294165 & - & -8132466 & - \\
\hline 31 & Jasa Perusahaan & -3510493.9 & - & -5132509.4 & - & -1780476 & - \\
\hline 32 & Real Estate dan Usaha Persewaan & 40807.1 & + & 328242.31 & + & 1784046 & + \\
\hline 33 & Jasa Pemerintahan Umum & -5488721 & - & -4235210.7 & - & 2113577 & + \\
\hline 34 & Jasa Pendidikan Pemerintah & -3294987.4 & - & -2637207.7 & - & 694319.7 & + \\
\hline 35 & Jasa Kesehatan Pemerintah & -2210981 & - & -1827384.5 & - & 115457.4 & + \\
\hline 36 & Jasa Pendidikan Swasta & -174473.7 & - & -50295.855 & + & 578640.8 & + \\
\hline 37 & Jasa Kesehatan Swasta & -1590592.7 & - & -1332423.2 & - & -24844.5 & - \\
\hline 38 & $\begin{array}{c}\text { Jasa Sosial Kemasyarakatan } \\
\text { Swasta Lainnya }\end{array}$ & -970849.6 & - & 5.66 & - & -106530 & - \\
\hline 39 & $\begin{array}{c}\text { Jasa Rekreasi, Kebudayaan dan } \\
\text { Olahraga }\end{array}$ & -537044.2 & - & -431306.83 & - & 104232.3 & + \\
\hline 40 & $\begin{array}{c}\text { Jasa Perorangan dan Rumah } \\
\text { Tangga, jasa lainnya }\end{array}$ & 486333.9 & + & 856638.02 & + & 2732157 & + \\
\hline
\end{tabular}




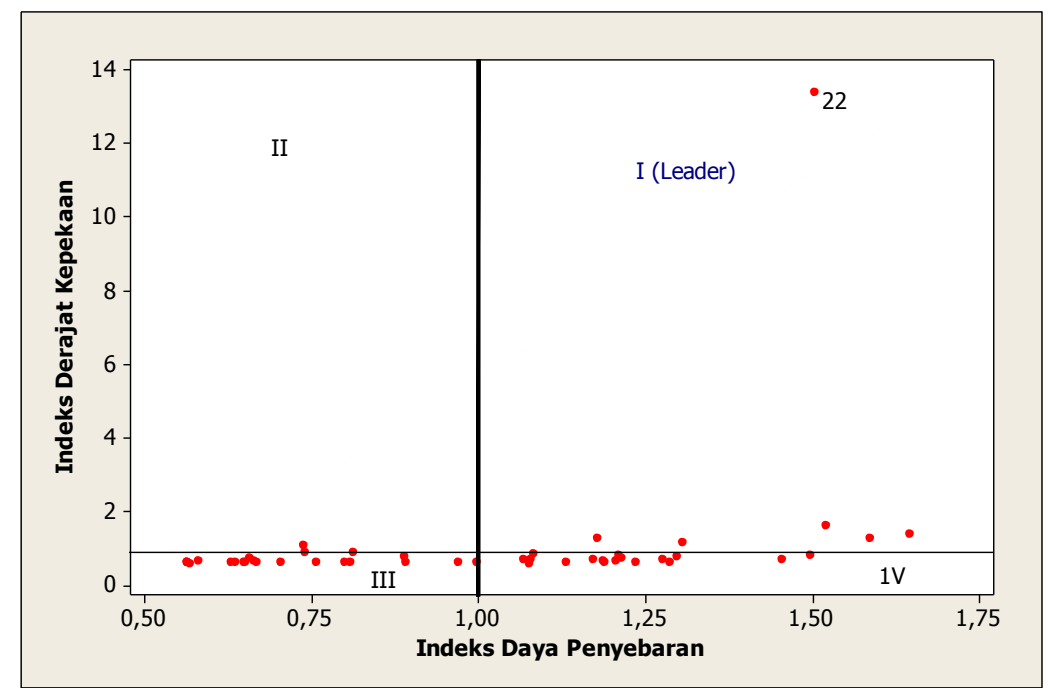

Gambar 2. Indeks Daya Penyebaran dan Derajat Kepekaan Kota Bandung

Komponen S menyatakan pergeseran differensial, jika suatu sektor pada komponen S bernilai positif maka sektor tersebut lebih tinggi daya saingnya ketimbang sektor yang sama pada perekonomian wilayah pembanding. Sebesar 33\% sektor ekonomi di Kota Bandung lebih tinggi daya saingnya dibandingkan sektor yang sama di Provinsi Jawa Barat. Lima sektor ekonomi dengan daya saingnya tertinggi adalah: sektor perdagangan, Industri tektil dan pakaian jadi, Jasa angkutan jalan, Industri makanan dan minuman, Jasa Komunikasi. Lima sektor ekonomi dengan daya saingnya terendah adalah: Hotel; Industri Kayu, Bambu, Rotan dan Furniture; Jasa Bank dan Lembaga Keuangan; Industri kendaraan Bermotor, karoseri, dan perlengkapannya; Industri Kimia dan Barang-Barang dari Kimia.

Komponen $\mathrm{M}+\mathrm{S}$ menggambarkan tingkat pertumbuhan, jika bertanda positif maka pertumbuhan sektor ekonomi tersebut pertumbuhannya lebih cepat dari rata-rata pertumbuhan sektor sejenis pada perekenomian wilayah pembanding. Sebesar $43 \%$ sektor ekonomi di Kota Bandung pertumbuhannya lebih cepat dari rata-rata pertumbuhan sektor yang sama di Provinsi Jawa Barat. Lima sektor yang pertumbuhannya paling cepat tersebut adalah: Industri Pengolahan Lainnya; Perdagangan; Industri Tekstil, Pakaian Jadi, Kulit dan alas kaki; Industri Makanan, Minuman dan Tembakau, Jasa Angkutan Jalan. Lima sektor yang pertumbuhannya paling lambat dibandingkan dengan sektor sejenis di Provinsi Jabar adalah: Industri Kayu, Bambu, Rotan dan Furniture; Hotel, Industri Percetakan dan Penerbitan; Industri Percetakan dan Penerbitan; Industri Kimia dan Barang-Barang dari Kimia.

\section{KESIMPULAN}

Sebesar $70 \%$ sektor ekonomi di Kota Bandung relatif maju dibandingkan dengan sektor yang sama di tingkat provinsi, dimana lima sektor relatif paling maju adalah: Industri Pengolahan Lainnya; Perdagangan; Industri tekstil dan pakaian jadi; Hotel; Industri makanan dan minuman. 33\% sektor ekonomi di Kota Bandung lebih tinggi daya saingnya dibandingkan sektor yang sama di Provinsi Jawa Barat. Lima sektor ekonomi dengan daya saingnya tertinggi adalah : sektor perdagangan, Industri tektil dan pakaian jadi, Jasa angkutan jalan, Industri makanan dan minuman, Jasa Komunikasi. 43\% sektor ekonomi di Kota Bandung pertumbuhannya lebih cepat dari rata-rata pertumbuhan sektor yang sama di Provinsi Jawa Barat. Lima sektor yang pertumbuhannya paling cepat tersebut adalah: Industri Pengolahan Lainnya; Perdagangan; Industri Tekstil, Pakaian Jadi, Kulit dan alas kaki; Industri Makanan , Minuman dan Tembakau, Jasa Angkutan Jalan. Sektor Perdagangan menjadi "top leader" bagi sektor-sektor lainnya, juga mempunyai daya saing dan pertumbuhannya paling cepat dibandingkan dengan sektor yang sama di Provinsi Jawa Barat, sehingga Sektor Perdagangan merupakan sektor unggulan Kota Bandung yang mempunyai daya saing komparatif maupun kompetitif di tingkat Jawa Barat. 


\section{UCAPAN TERIMA KASIH}

Penelitian ini merupakan bagian dari penelitian hibah bersaing yang didanai oleh Dikti tahun anggaran 2017, dengan skema Penelitian Produk Terapan.

\section{DAFTAR PUSTAKA}

Amir, Hidayat, dkk. (2005). Jurnal Keuangan dan Moneter. Analisis Sektor Unggulan Untuk Evaluasi Kebijakan Pembangunan Jawa Timur Menggunakan Tabel Input-Output 1994 Dan 2000. Departemen Keuangan RI. Edisi Desember 2005.

BPS Kota Bandung. (2010). Tabel Input Output Kota Bandung Tahun 2008. BPS Kota Bandung. BPS dan Bapeda Jawa Barat. (2010). Tabel Input Output Kota Bandung 2010. Bandung.

Pemerintah kota Bandung (2013) Visi dan Misi Walikota Bandung Tahun 2013-2018 diunduh tanggal 10 Juli melalui standarpelayanan.bandung.go.id/.../ fe9ba982d4a0a9b1745c75354f...

Nazara, Suahasil (2005). Analisis Input-Output. Edisi Kedua. LP-FEUI. Jakarta

Ronald E, Miller and Peter D. Blair. (1985). Input-Output Analysis, Prentice-Hall, Inc. Englewood Cliffs, New Jersey. 